\title{
Event-Triggered Control and Application for A Class of Nonlinear Multi-Agent Systems With Time Delay
}

Jiancheng Zhang ( $\nabla$ zhangjianchenghit@126.com )

Harbin Institute of Technology https://orcid.org/0000-0002-6103-7793

\section{Xinsheng Wang}

Harbin Institute of Technology

Qi Cao

Harbin Institute of Technology

\section{Research Article}

Keywords: Event-triggered consensus, multi-agent system, nonlinear dynamics, time delay

Posted Date: June 16th, 2021

DOl: https://doi.org/10.21203/rs.3.rs-604407/v1

License: (1) This work is licensed under a Creative Commons Attribution 4.0 International License.

Read Full License 


\section{Abstract}

Linear multi-agent systems (MAS) have been studied a lot. Since nonlinear MAS with time delay and directed graph by using the event-triggered technique are seldom studied, the distributed control of a class of nonlinear leader-following MAS is considered in this paper. Firstly, we linearize the nonlinear MAS composed of $\mathrm{N}$ agents with directed graph by feedback, and transform the research object into a linear system. Furthermore, we proposed an event-triggered consensus algorithm for the leader-following MAS. Then we prove the consensus of the proposed algorithm by using related theorems. It is proved that the algorithm converges exponentially and avoids Zeno-behavior of triggering time sequences. Finally, we apply the designed event-triggered consensus algorithm to an engineering example. A simulation system is established in Matlab environment and the simulation example results verify the effectiveness of the proposed algorithm. It effectively reduces the number of communication among agents and achieves the consistency of control objectives.

\section{Full Text}

This preprint is available for download as a PDF.

\section{Figures}




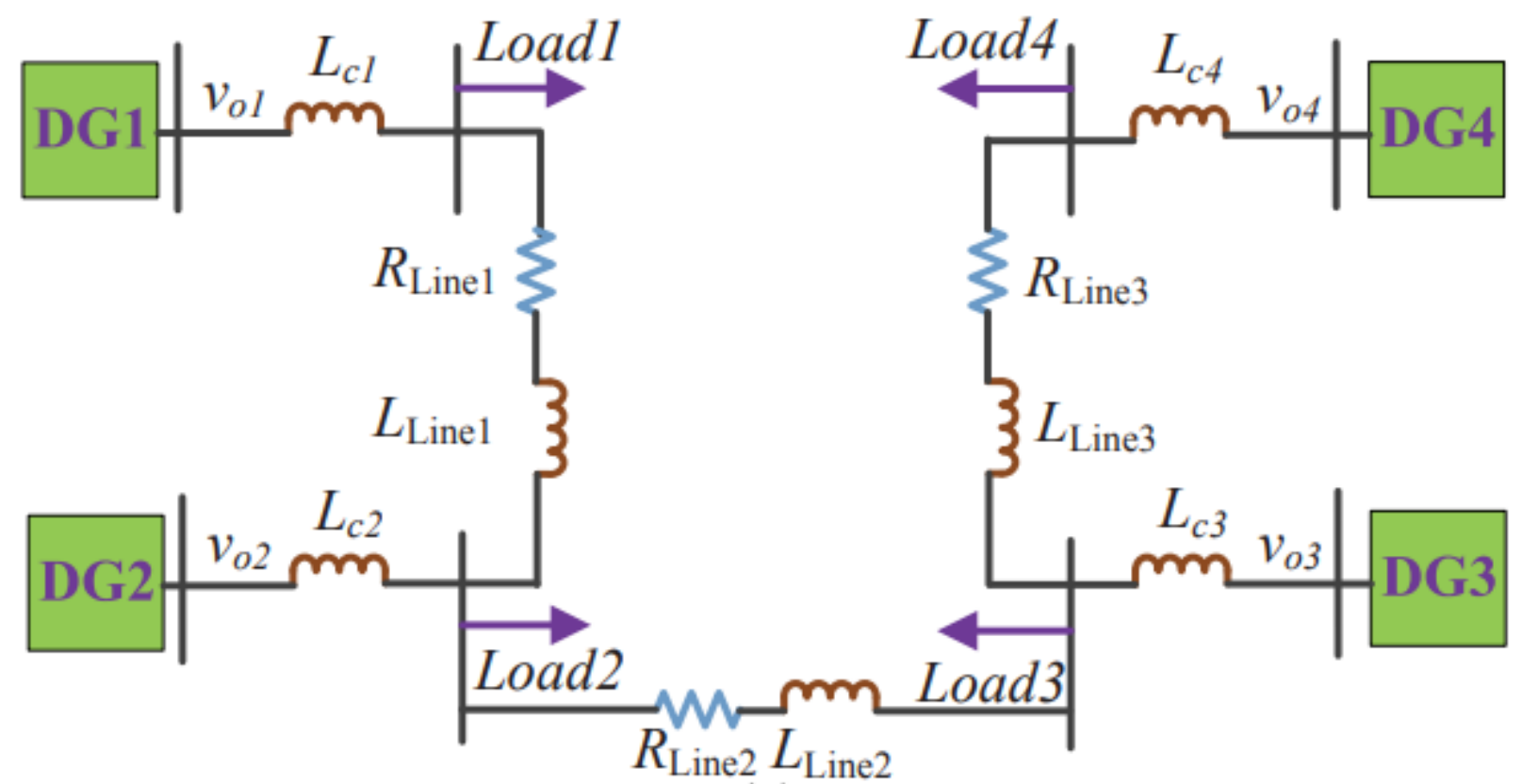

(a)

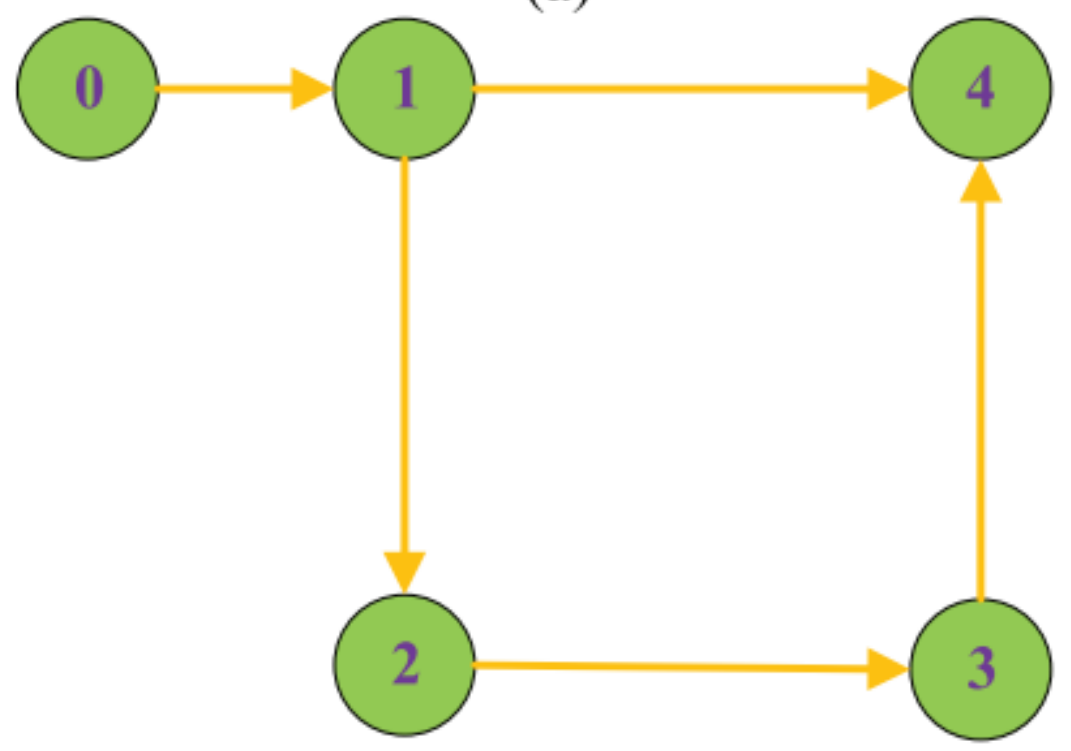

(b)

Figure 1

Microgrid structure diagram. (a) Schematic of the physical system (b) Communication network 


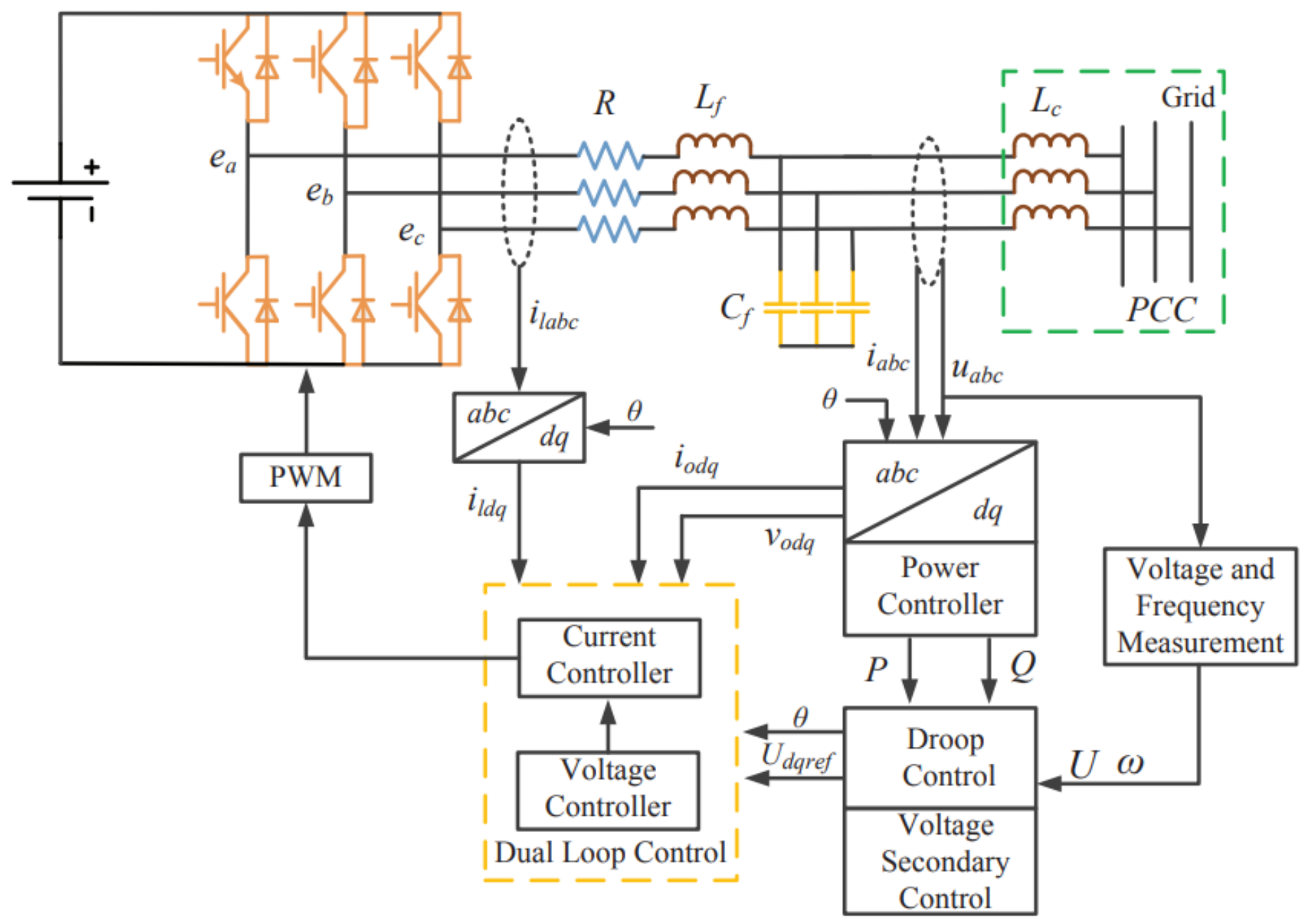

Figure 2

The internal structure of each DG

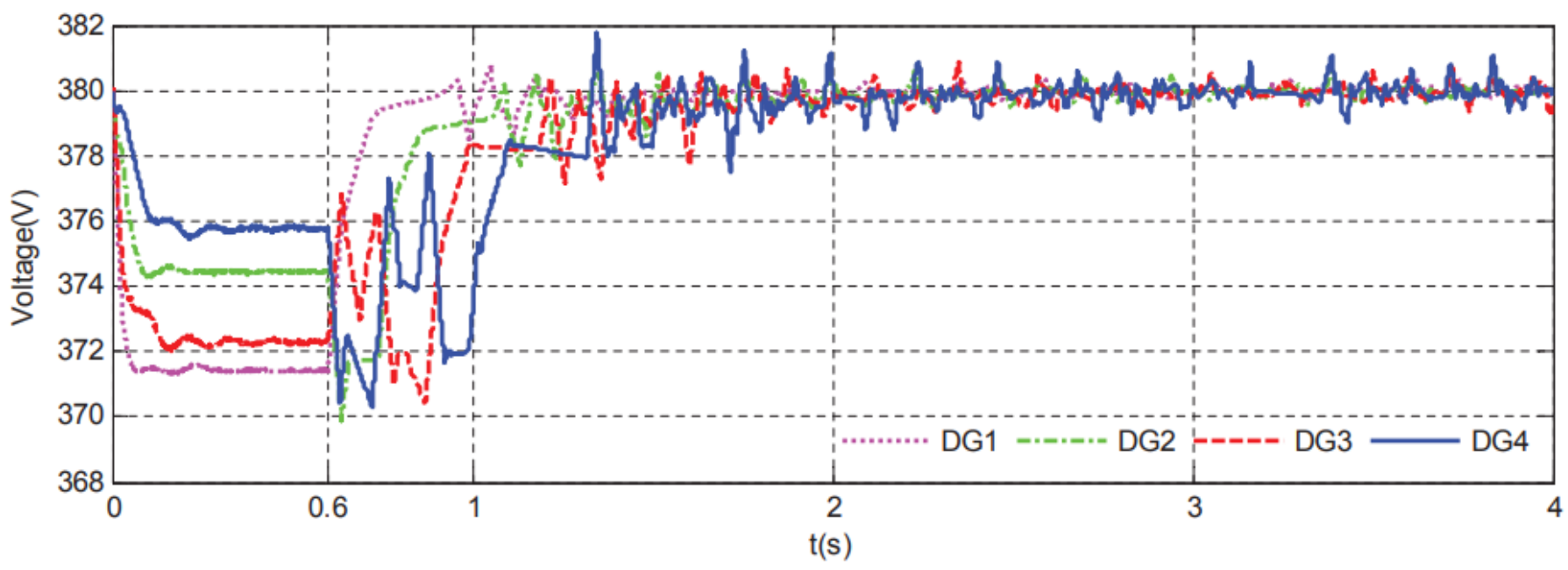

Figure 3

Voltage of MAS 


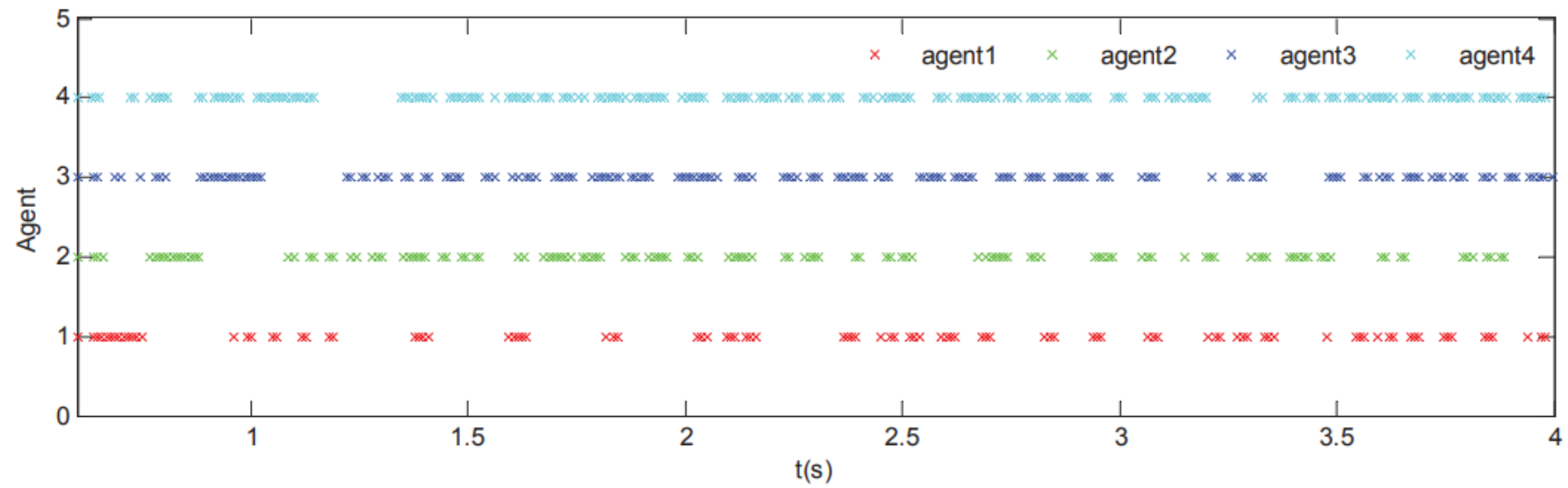

Figure 4

Triggering instants of agents 